\title{
Mechanical and Imaging Properties of a Clinical-Grade Kidney Phantom Based on Polydimethylsiloxane and Elastomer
}

\author{
Izdihar Kamal 1,2 (D), Hairil Rashmizal Abdul Razak ${ }^{3}{ }^{(D}$, Muhammad Khalis Abdul Karim $^{2, *(D)}$, \\ Syamsiah Mashohor ${ }^{4}$, Josephine Ying Chyi Liew ${ }^{2} \mathbb{D}$, Yiin Jian Low ${ }^{2}$, Nur Atiqah Zaaba ${ }^{1,5}$, \\ Mazlan Norkhairunnisa ${ }^{6}$ and Nur Athirah Syima Mohd Rafi ${ }^{1}$
}

Citation: Kamal, I.; Razak, H.R.A.; Abdul Karim, M.K.; Mashohor, S.; Liew, J.Y.C.; Low, Y.J.; Zaaba, N.A.; Norkhairunnisa, M.; Rafi, N.A.S.M. Mechanical and Imaging Properties of a Clinical-Grade Kidney Phantom Based on Polydimethylsiloxane and Elastomer. Polymers 2022, 14, 535.

https://doi.org/10.3390/ polym 14030535

Academic Editors: Ick-Soo Kim and Carmine Coluccini

Received: 29 September 2021 Accepted: 10 December 2021 Published: 28 January 2022

Publisher's Note: MDPI stays neutral with regard to jurisdictional claims in published maps and institutional affiliations.

Copyright: (C) 2022 by the authors. Licensee MDPI, Basel, Switzerland. This article is an open access article distributed under the terms and conditions of the Creative Commons Attribution (CC BY) license (https:// creativecommons.org/licenses/by/ $4.0 /)$.
1 Department of Medical Imaging, School of Health Sciences, KPJ Healthcare University College, Nilai 71800, Negeri Sembilan, Malaysia; izdihar.kamal@kpjuc.edu.my (I.K.);

Ieqa_zz@yahoo.com.my (N.A.Z.); tirasyima@gmail.com (N.A.S.M.R.)

2 Department of Physics, Faculty of Science, University of Putra Malaysia, Seri Kembangan 43400, Selangor, Malaysia; josephine@upm.edu.my (J.Y.C.L.); yiinjian5447@gmail.com (Y.J.L.)

3 Department of Radiology, Faculty of Medicine and Health Sciences, University of Putra Malaysia, Seri Kembangan 43400, Selangor, Malaysia; rashmizal@upm.edu.my

4 Department of Computer and Communication Systems, Faculty of Engineering, University of Putra Malaysia, Seri Kembangan 43400, Selangor, Malaysia; syamsiah@upm.edu.my

5 Diagnostic Imaging Services, KPJ Seremban Specialist Hospital, Lot 6219\&6220, Jalan Toman 1 Kemayan Square, Seremban 70200, Negeri Sembilan, Malaysia

6 Institute of Advanced Technology, University of Putra Malaysia, Seri Kembangan 43400, Selangor, Malaysia; norkhairunnisa@upm.edu.my

* Correspondence: mkhalis@upm.edu.my; Tel.: +60-192140612

\begin{abstract}
Medical imaging phantoms are considered critical in mimicking the properties of human tissue for calibration, training, surgical planning, and simulation purposes. Hence, the stability and accuracy of the imaging phantom play a significant role in diagnostic imaging. This study aimed to evaluate the influence of hydrogen silicone (HS) and water $\left(\mathrm{H}_{2} \mathrm{O}\right)$ on the compression strength, radiation attenuation properties, and computed tomography (CT) number of the blended Polydimethylsiloxane (PDMS) samples, and to verify the best material to simulate kidney tissue. Four samples with different compositions were studied, including samples S1, S2, S3, and S4 which consisted of PDMS 100\%, HS/PDMS 20:80, $\mathrm{H}_{2} \mathrm{O} / \mathrm{PDMS}$ 20:80, and HS/ $\mathrm{H}_{2} \mathrm{O} / \mathrm{PDMS}$ 20:40:40, respectively. The stability of the samples was assessed using compression testing, and the attenuation properties of sample S2 were evaluated. The effective atomic number of S2 showed a similar pattern to the human kidney tissue at $1.50 \times 10^{-1}$ to $1 \mathrm{MeV}$. With the use of a $120 \mathrm{kVp}$ X-ray beam, the CT number quantified for S2, as well measured $40 \mathrm{HU}$, and had the highest contrast-to-noise ratio (CNR) value. Therefore, the S2 sample formulation exhibited the potential to mimic the human kidney, as it has a similar dynamic and is higher in terms of stability as a medical phantom.
\end{abstract}

Keywords: compression strength; effective atomic number; imaging properties; CT number; kidney phantom

\section{Introduction}

Medical imaging has proven its critical role in the healthcare field due to its ability to act as a valuable tool in diagnosis, therapy, surgical planning, postoperative assessment, and planning in radiotherapy treatment [1]. The increased volume of imaging procedures and the complexity of pathologies has led researchers to optimize the function at its highest standard performance. Often, the clinical diagnosis, which solely depends on a radiologist's interpretation, takes time. A large volume of cases received daily tends to lead to errors, which may later cause misdiagnosis in patients [2]. This amenable side of medical imaging has been compensated with the introduction of quantitative imaging. The potential of 
quantitative imaging as biomarkers for many diseases such as brain ischemia, coronary artery disease, interstitial lung disease, and colorectal issues has become substantial in current radiology practice [3]. The growing need to employ quantitative imaging in clinical settings has motivated the study on the development of imaging phantoms [4,5]. For example, in the computed tomography (CT) examination, the standardization of CT pixel values with the Hounsfield Unit (HU) acts as vital measure to characterize tissue density, which is a vital component of quantitative imaging application [6,7]. This study presented the threshold values of radiation attenuation by the anthropomorphic phantom sample, including image quality, for a better understanding of the performance.

Briefly, the anthropomorphic phantom is critical in the quality control of modalities, as it allows the physicist to perform the calibration test, dose verification, teaching aid, and surgical guidance. The phantoms are usually made of materials that have human tissue equivalency and were designed with similar attenuation properties $[3,8]$. However, most of the designed phantoms face long-term stability issues. Usually, the agar and water-based gels phantoms demonstrate changes over time, due to continuous water expulsion and absorption cycles. Furthermore, the new invention of phantoms using the 3D-printing technique has limitations as well, including the lack of materials to mimic all the tissue properties and the high cost compared with other fabrication techniques [9].

The computed tomography (CT) scanner has been considered a gold-standard technique that has good accuracy, is faster in the detection of renal diseases, and has a much lower cost than the magnetic resonance imaging (MRI) scanner [10]. As the prevalence of renal diseases is often caused by incidental findings on abdominal CT images, an advanced approach is required to facilitate the early detection of renal diseases [11]. However, radiation exposure is still the primary concern as radiation is associated with radiation-induced toxicity, although this is underappreciated $[12,13]$. This study proposes the potential of a blend of Polydimethylsiloxane (PDMS) as a base of the kidney phantom material. PDMS has an elastic modulus of $360-870 \mathrm{kPa}$, which is larger than the elastic modulus of a real kidney [14]. Therefore, this research attempted to modify the PDMS with hydrophilic silicone and water, so that it can be a simple and economically affordable phantom with higher reproducibility of human tissue [15]. Additionally, this elastomeric polymer has ideal features such as nontoxicity, biocompatibility, blood compatibility, elasticity, transparency, and higher durability. There are several PDMS formulations, and those with Sylgard 184 are most often used in biological studies.

Clinically valid phantoms should demonstrate similar human tissue properties; hence, they should be designed with materials that have the same attenuation characteristics. For this purpose, the CT numbers and the image quality of the samples were evaluated to identify the relation of radiation properties and imaging properties to further validate the mechanical and chemical properties of the blended PDMS samples.

\section{Materials and Methods}

\subsection{Fabrication of PDMS Phantom}

The solid tissue-mimicking phantoms were fabricated from PDMS (Dow Corning, Michigan, US) with a standard density of $0.965 \mathrm{~g} / \mathrm{cm}^{3}$ and viscosity (mixed) of $3500 \mathrm{cps}$. The base was a silicone-based polymer, belonging to the group of silicone elastomers. The typical mixing ratio for PDMS is a ten-part base and one-part curing agent (dimethyl vinylated and trimethylated silica, respectively) [16]. Different base/agent ratios of the PDMS network means a different amount of cross-linking [17]. Four samples were made with distinct material composition, as presented in Table 1, specifically: PDMS 100\%, $\mathrm{HS} / \mathrm{PDMS}$ 20:80, $\mathrm{H}_{2} \mathrm{O} / \mathrm{PDMS}$ 20:80, $\mathrm{HS} / \mathrm{H}_{2} \mathrm{O} / \mathrm{PDMS}$ 20:40:40.

Initially, the elastomer base and the corresponding curing agent were weighed using an analytical balance, according to the predetermined weightage (Denver Instrument P-214, Brentwood, NY, US). Both solutions were then thoroughly mixed and stirred using a hot plate magnetic stirrer for five minutes. Before the mixture was poured onto a petri dish, a passivation layer (Ease Release 200) was applied to the petri dish to prevent strong 
adhesion between the mixture and the surface of the dish. The sample was then degassed in a vacuum desiccator for $30 \mathrm{~min}$ to remove any bubbles. The mixture was then heated in an oven at $80^{\circ} \mathrm{C}$ for half an hour, and the temperature was increased to $100{ }^{\circ} \mathrm{C}$ for another one hour. Afterwards, the cured sample was left to cool at room temperature. After the PDMS network mold cured, the sample was stable and could be stored for months.

Table 1. Chemical composition of the Polydimethylsiloxane (PDMS) sample.

\begin{tabular}{cccc}
\hline Samples & $\begin{array}{c}\text { Hydrogen Silicone (g) } \\
\mathbf{C}_{7} \mathbf{H}_{22} \mathbf{O}_{2} \mathbf{S i}_{3}\end{array}$ & $\mathbf{H}_{2} \mathbf{O}(\mathrm{g})$ & $\begin{array}{c}\mathbf{P D M S}(\mathrm{g}) \\
\mathbf{C}_{2} \mathbf{H}_{6} \mathbf{O} \mathbf{i}\end{array}$ \\
\hline $\mathrm{S} 1$ & 0 & 0 & 20 \\
$\mathrm{~S} 2$ & 4 & 0 & 16 \\
$\mathrm{~S} 3$ & 0 & 4 & 16 \\
$\mathrm{~S} 4$ & 4 & 8 & 8 \\
\hline
\end{tabular}

\subsection{Compression Testing}

The compressive test was performed by using an Instron universal compression-testing machine (Figure 1) with a $500 \mathrm{~N}$ load cell based on ASTM D1621 plastic compression testing. The phantom samples were first punched to cut the PDMS samples into cylindrical shapes. The initial dimensions were measured by a digital vernier caliper before testing, with an average value recorded from at least five measurements for each dimension: (i) $25.4 \mathrm{~mm}$ diameter and $25.4 \mathrm{~mm}$ height for cylinder-shaped compressive specimens. As shown in Figure 2, each sample was replicated 5 times in order to achieve the average reading for the compression test. The cylindrical samples were then placed on the compression testing plate, and the load cell was slowly lowered until it touched the surface of the sample. The contact between the sample and the plate was ensured by slowly moving the plate down until the machine detected the load. This test was conducted at a rate of $0.050 \pm 0.010 \mathrm{in} / \mathrm{min}$, as shown in Figure 2. From the stress-strain curve, the modulus of elasticity (MOE) can be calculated based on the following formula [14]:

$$
E=\frac{\sigma}{\varepsilon}
$$

where $E$ is the slope of the line in this region, and stress $(\sigma)$ is proportional to strain $(\varepsilon)$.

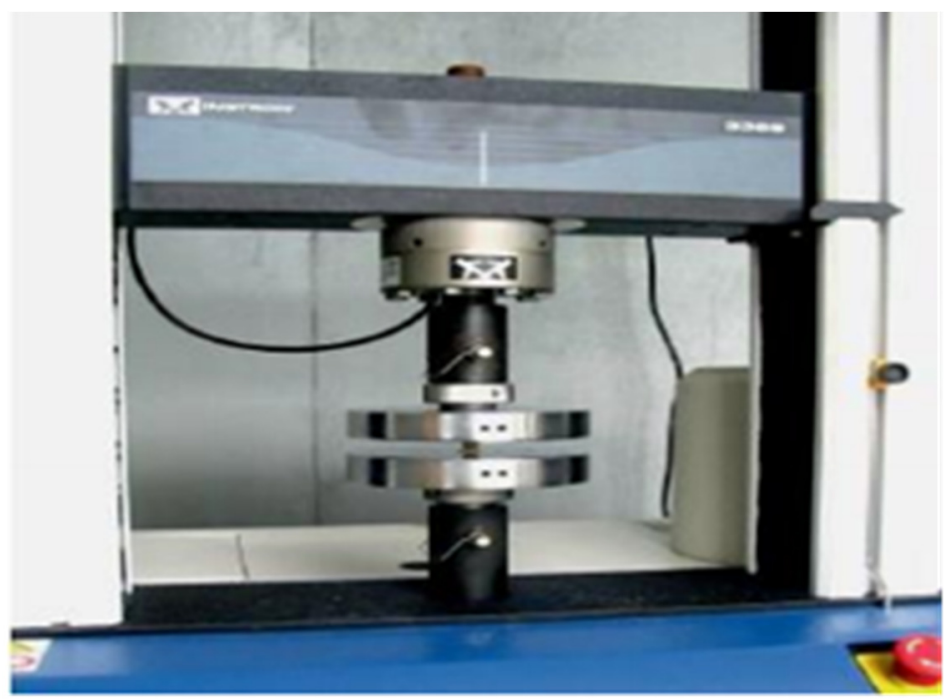

Figure 1. Instron universal compression-testing used for the compression test. 


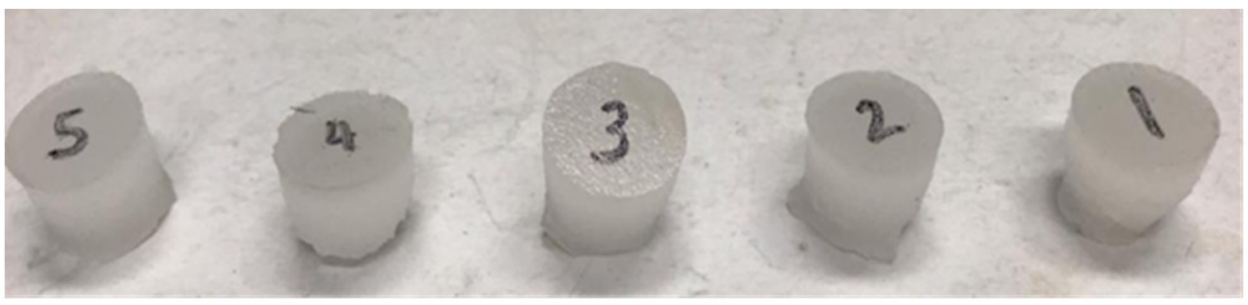

Figure 2. Cylindrical blend HS/PDMS 20:80 network for compression test.

\subsection{Radiation Attenuation Properties}

In this study, we evaluated the tissue equivalence of the phantom by using a web-based software, Phy-X/PSD (Ataturk University, Erzurum, TR). The software is a web-based simulator that has a user friendly GUI interface, used to calculate $Z_{\text {eff }}$ in the energy region of $1 \mathrm{keV}-20 \mathrm{MeV}$ for photons (both photon interactions and photon energy absorption) and in the energy region of $1 \mathrm{MeV}-1 \mathrm{GeV}$ for electrons, protons, alpha particles, and ions $[18,19]$. The tissue equivalence of the tissue substitutes is represented by this method for the computation of effective atomic numbers in this study. The methods for measuring $\mathrm{Z}_{\mathrm{eff}}$ are discussed next. The first phase was concerned with the implementation of the chemical composition from the content to the software. The total weight number and fractions of the mole should be equal to 1 (or 100 percent). For example, sample 1 (mass) constituent fractions are $0.8 \mathrm{C}_{2} \mathrm{H}_{6} \mathrm{OSi}+0.2 \mathrm{C}_{7} \mathrm{H}_{22} \mathrm{O}_{2} \mathrm{Si}_{3}$. Anything more may be measured at the same time as one item. The "+" sign can be used to incorporate other simultaneous material- $Z_{\text {eff }}$ calculations. The software generated the interaction photon data in the energy regions for ions and charged particle interactions, pertinent to the context of medical physics ( $1 \mathrm{keV}$ to $20 \mathrm{MeV}$ for pho and $1 \mathrm{MeV}$ to $1 \mathrm{GeV}$ for tons of charged particles). The $Z_{\text {eff }}$ in the case of continuous energy is defined as the output data.

\subsection{Imaging Properties}

In this study, the prepared phantoms were scanned using a 64-slice CT scanner (Somatom Definition Flash: Siemens Healthcare, Munich, DE) for the evaluation of imaging properties. Phantom samples were aligned and placed perpendicularly on the CT scanning couch before the scanning process. The scanning acquisition parameter was set accordingly with a detector configuration of $64 \times 0.625$, beam collimation of $0.5 \mathrm{~mm}$, gantry rotation speed of $0.5 \mathrm{~s}$, pitch of 1.375, and tube potentials of $80 \mathrm{kVp}, 100 \mathrm{kVp}, 120 \mathrm{kVp}$, and $140 \mathrm{kVp}$, with fixed-tube currents [20]. The images were reconstructed using a single filter kernel with $1 \mathrm{~mm}$ sections at $0.5 \mathrm{~mm}$ intervals.

After data images were obtained, the CT number of each sample was assessed and compared to that of human tissue features in CT scan images. The post-processing imaging tool was utilized to extract the CT numbers and noise values by placing the circular region of interest (ROI) in the selected image (Figure 3). The obtained value was then compared to the typical CT numbers of normal human tissue, particularly that of the kidney. The information regarding the CT numbers and noise was used to calculate the signal-to-noise ratio (SNR) and contrast-to-noise ratio (CNR) [21]. In a digital image, the signal is defined as a resultant exposure demonstrated on the image display monitor. Along with the exposure, there is an electronic noise that may be visualized along with the displayed image. The signal-to-noise ratio (SNR) is a method of measuring object detectability relative to noise in the digital image [21]. Higher image quality can be obtained by increasing the strength of the signal, which results in higher SNR than the amount of noise. Furthermore, the visibility of the anatomical details also depends on the SNR, where increasing the SNR increases the visibility of anatomic details and vice versa. Scientifically, the SNR in the 
region of interest (ROI) can be described as the ratio between the mean $\mathrm{CT}$ number of the $\mathrm{ROI}\left(H U_{R O I}\right)$ and the associated SD of the ROI $\left(S D_{R O I}\right)$ expressed as [22]:

$$
S N R=\frac{H U_{R O I}}{S D_{R O I}}
$$

and

$$
C N R=\frac{H U_{R O I}-H U_{B}}{S D_{B}}
$$

where $H U_{B}$ and $S D_{B}$ are the background $C T$ number and noise of the nearest region, respectively.

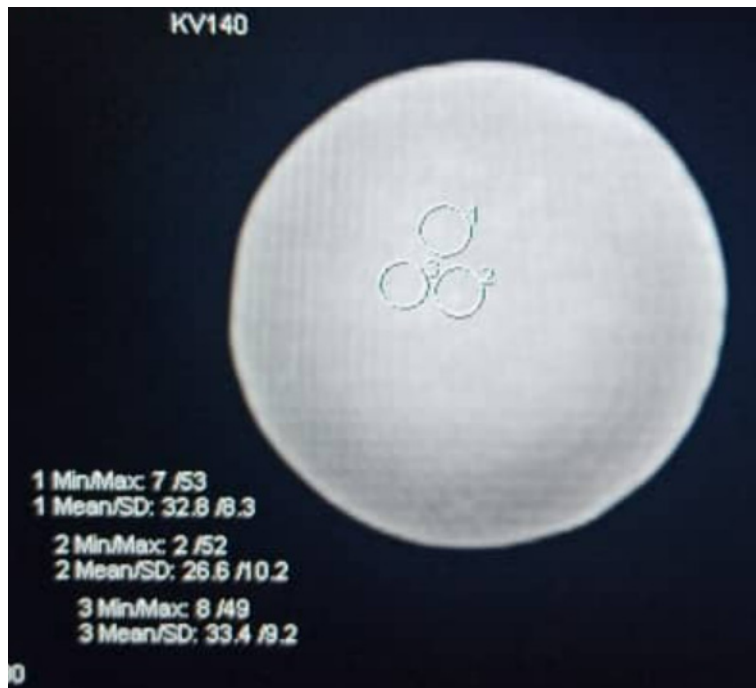

Figure 3. Example of objective image quality analysis to assess the CT number (mean) and image noise (SD) by putting the circular region of interest (ROI) in the middle of the sample.

\section{Results}

Compression testing was performed on all the developed cylindrical phantom samples to characterize the compressive properties of materials. The samples yielded different compressive strengths and young modulus ranging from 0.41 to $4.06 \mathrm{MPa}$ (Table 2). According to the table below, the HS/PDMS 20:80 sample had the highest compressive strength among all the samples.

Table 2. Composition ration of each sample and compression strength.

\begin{tabular}{cccccc}
\hline Samples & $\begin{array}{c}\text { Hydrogen Silicone } \\
\mathbf{C}_{\mathbf{7}} \mathbf{H}_{\mathbf{2} 2} \mathbf{O}_{\mathbf{2}} \mathbf{S i}_{\mathbf{3}}\end{array}$ & $\begin{array}{c}\text { Water } \\
\mathbf{H}_{\mathbf{2}} \mathbf{O}\end{array}$ & $\begin{array}{c}\text { PDMS } \\
\mathbf{C}_{\mathbf{2}} \mathbf{H}_{\mathbf{6}} \mathbf{O} \mathbf{i}\end{array}$ & $\begin{array}{c}\text { Compression } \\
\text { Testing (MPa) }\end{array}$ & $\begin{array}{c}\text { Young Modulus } \\
\mathbf{( M P a}\end{array}$ \\
\hline PDMS 100\% & 0 & 0 & 20 & $2.6-2.8^{*}$ & $2.61^{*}$ \\
$\mathrm{HS} /$ PDMS 20:80 & 4 & 0 & 16 & $4.06 \pm 0.62$ & 4.17 \\
$\mathrm{H}_{2} \mathrm{O} /$ PDMS 20:80 & 0 & 4 & 16 & $1.09 \pm 0.362$ & 1.19 \\
$\mathrm{HS} / \mathrm{H}_{2} \mathrm{O} /$ PDMS 20:40:40 & 4 & 8 & 8 & $0.41 \pm 0.05$ & 0.516 \\
\hline
\end{tabular}

${ }^{*}$ reported by other researchers [23-25].

Compressive strength was measured to determine the compressive force that the blended PDMS samples could withstand while retaining their shape. Changes were observed in all samples; however, the magnitude of this change varied. As can be seen from Table 2, the compressive stresses and young modulus were highest for sample HS/PDMS 20:80 (4.06 MPa) and the lowest value was recorded for sample HS/ $\mathrm{H}_{2} \mathrm{O} / \mathrm{PDMS}$ 20:40:40 as it crushed faster. This is due to less PDMS in the sample, whereas sample HS/PDMS 20:80 had the highest as the existence of HS and nil water. Silicone has a high atomic number; thus, it produced a stronger sample. Therefore, the mass fraction of silicone and water 
played a critical role in the mechanical properties of the sample [26]. On top of that, the strength of pure PDMS decreased by 30\%, compared with the HS/PDMS 20:80 sample as $\mathrm{HS}$ was not added in the sample. Furthermore, the strength of the sample $\mathrm{H}_{2} \mathrm{O} / \mathrm{PDMS}$ 20:80 was lower than pure PDMS by double, as water diluted the PDMS sample.

Based on the earlier analyses, HS/PDMS 20:80 is believed to be an optimum sample with the highest compressive strength. Therefore, further evaluation in terms of radiation attenuation properties was conducted for this PDMS sample, as this phantom will be used for dosimetry and calibration. The photon interaction with the matter was assessed based on the mass attenuation $(\mu / p)$ parameter. The mass attenuation coefficient (MAC), effective atomic number $\left(\mathrm{Z}_{\mathrm{eff}}\right)$, half-value layer (HVL), equivalent atomic number $\left(\mathrm{Z}_{\mathrm{eq}}\right)$, and linear atomic coefficient (LAC) of the HS/PDMS 20:80 sample are tabulated in Table 3.

Table 3. Radiation attenuation properties of HS/PDMS 20:80.

\begin{tabular}{cccccc}
\hline \multirow{2}{*}{$\begin{array}{c}\text { Energy } \\
(\mathbf{M e V})\end{array}$} & $\mathbf{M A C}\left(\mathbf{c m}^{\mathbf{2}} \mathbf{g} \mathbf{)}\right.$ & \multicolumn{3}{c}{ Attenuation Properties } \\
\cline { 2 - 6 } & 4.586 & $\mathbf{Z}_{\text {eff }}$ & $\mathbf{H V L}$ & $\mathbf{Z}_{\mathbf{e q}}$ & $\mathbf{L A C}$ \\
\hline $1.50 \times 10^{-2}$ & 2.044 & 11.38 & 0.15661 & 10.33 & 4.568 \\
$2.00 \times 10^{-2}$ & 0.736 & 7.29 & 0.3514 & 10.43 & 2.037 \\
$3.00 \times 10^{-2}$ & 0.417 & 6.26 & 1.72455 & 10.62 & 0.416 \\
$4.00 \times 10^{-2}$ & 0.300 & 5.34 & 2.3926 & 10.67 & 0.300 \\
$5.00 \times 10^{-2}$ & 0.246 & 4.83 & 2.91631 & 10.7 & 0.247 \\
$6.00 \times 10^{-2}$ & 0.198 & 4.35 & 3.62052 & 10.75 & 0.199 \\
$8.00 \times 10^{-2}$ & 0.176 & 4.16 & 4.06981 & 10.78 & 0.177 \\
$1.00 \times 10^{-1}$ & 0.150 & 4.00 & 4.79128 & 10.83 & 0.15 \\
$1.50 \times 10^{-1}$ & 0.135 & 3.96 & 5.31868 & 10.85 & 0.136 \\
$2.00 \times 10^{-1}$ & 0.116 & 3.93 & 6.18157 & 10.88 & 0.117 \\
$3.00 \times 10^{-1}$ & 0.104 & 3.92 & 6.92316 & 10.89 & 0.104 \\
$4.00 \times 10^{-1}$ & 0.095 & 3.92 & 7.59245 & 10.9 & 0.095 \\
$5.00 \times 10^{-1}$ & 0.087 & 3.92 & 8.21515 & 10.91 & 0.088 \\
$6.00 \times 10^{-1}$ & 0.077 & 3.91 & 9.35973 & 10.91 & 0.077 \\
$8.00 \times 10^{-1}$ & 0.069 & 3.91 & 10.41402 & 10.91 & 0.069 \\
1.00 & 0.056 & 3.92 & 12.79181 & 8.76 & 0.056 \\
1.50 & 0.048 & 3.93 & 14.87477 & 8.48 & 0.048 \\
2.00 & 0.039 & 3.99 & 18.42066 & 8.42 & 0.039 \\
3.00 & 0.034 & 4.05 & 21.3392 & 8.39 & 0.034 \\
4.00 & 0.030 & 4.13 & 23.78665 & 8.38 & 0.03 \\
5.00 & 0.028 & 4.21 & 25.84345 & 8.38 & 0.028 \\
6.00 & 0.025 & 4.37 & 29.07043 & 8.37 & 0.025 \\
8.00 & 0.023 & 4.52 & 31.42182 & 8.37 & 0.023 \\
1.00 & 0.021 & 35.01704 & 8.36 & 0.021 \\
1.50 & & & & \\
\hline
\end{tabular}

Several works measured the LAC within the diagnostic radiology energy range, which was from 30 to $110 \mathrm{keV}$ [27-29]. The calculated LAC for PDMS samples were compared with these previous works, and this comparison is shown in Table 4. This comparison shows that the values calculated in the present method agree with previous measurements and other theoretical data found in the literature for the energy range of $50 \mathrm{keV}$ to $100 \mathrm{keV}$.

Table 4. LAC of HS/PDMS 20:80 and compared with other studies.

\begin{tabular}{ccccc}
\hline Energy (keV) & HS/PDMS 20:80 & $\begin{array}{c}\text { King et al. } \\
\mathbf{( 2 0 1 1 )}[27]\end{array}$ & $\begin{array}{c}\text { Aysun Böke } \\
\mathbf{( 2 0 1 4 )}[28]\end{array}$ & $\begin{array}{c}\text { Manjunath et al. } \\
\mathbf{( 2 0 1 5 )}[29]\end{array}$ \\
\hline 30 & 0.710 & 0.389 & 0.383 & 0.384 \\
40 & 0.402 & 0.279 & 0.277 & 0.278 \\
50 & 0.290 & 0.246 & 0.233 & 0.241 \\
60 & 0.238 & 0.218 & 0.213 & 0.215 \\
80 & 0.191 & 0.201 & 0.191 & 0.196 \\
\hline
\end{tabular}


The HS/PDMS 20:80 sample was scanned using the Somatom Definition Flash with varying $\mathrm{kVp}$ values to correlate the relationship between different $k V p$ and $H U$ values. Table 5 tabulates the $\mathrm{HU}$ values at $80 \mathrm{kVp}, 100 \mathrm{kVp}, 120 \mathrm{kVp}$, and $140 \mathrm{kVp}$. The values varied from $14-130 \mathrm{HU}$, and specifically for $120 \mathrm{kVp}$, the CT number was $40-60 \mathrm{HU}$, within the range of the kidney's CT number. The CT number decreased from $100 \mathrm{kVp}$ to $140 \mathrm{kVp}$. As recommended by the American College of Radiology (ACR), a CT number study should be performed between 120 and $130 \mathrm{kVp}$ [30]. Based on Table 5, at 120 and $140 \mathrm{kVp}$, the $\mathrm{CT}$ number was lower, and these values correspond to the values of the kidney, muscle, blood, and liver. Tailoring the concentrations of PDMS, $\mathrm{HS}$ and $\mathrm{H}_{2} \mathrm{O}$ would enable samples to be produced for specific parts of selected organs [31]. Additionally, Table 5 shows the contrast-to noise-ratio (CNR) and signal-to-noise ratio (SNR) for all tube potentials. Notably, the highest CNR occurring at $120 \mathrm{kVp}$ was consistent and aligned with the ACR recommendation to choose a $120 \mathrm{kVp}$ scan for a phantom study [6].

Table 5. Average CT number, standard deviation (SD) and image quality of the samples.

\begin{tabular}{cccccccc}
\hline $\mathbf{k V p}$ & $\begin{array}{c}\text { Average CT } \\
\text { Number }\end{array}$ & SD ROI & $\begin{array}{c}\text { HU } \\
\text { Background }\end{array}$ & $\begin{array}{c}\text { SD } \\
\text { Background }\end{array}$ & SNR & CNR \\
\hline 80 & 71 & 7.5 & -802 & 10.3 & 15.12 & 87.11 \\
100 & 63.7 & 6 & -792 & 9.5 & 14.66 & 96.18 \\
120 & 45 & 5.6 & -789 & 8.2 & 2.56 & 100.9 \\
140 & 30 & 8.3 & -830 & 84.7 & 1.1 & 9.98 \\
\hline
\end{tabular}

\section{Discussion}

According to Umale et al., the ultimate stress for human kidney varies from $2.8 \mathrm{MPa}$ to $10.9 \mathrm{MPa}$, whereas this study reported $4.06 \mathrm{MPa}$ for compression strength [8]. The elastic modulus of a real kidney was $180.32 \pm 11.11 \mathrm{kPa}($ mean $\pm \mathrm{SD}$ ) and $95.64 \pm 9.39 \mathrm{kPa}$ under axial and transversal loadings, respectively. Information about the mechanical properties of human tissue will aid medical and biomechanical purposes to be used for diagnosis and simulation, respectively. The amount of water inside the sample may result in the fluctuation of the compressive strength over time, with the strength decreasing after weeks. The decrease in strength was prominent for higher amounts of water. Thus, it is advisable to fabricate a solid phantom that is not made of water-based material. On the other hand, the addition of HS increased the [SiR2-o-] backbone structure instead of the carbon backbone, thus adding photo-catalysts of the functional group, which can adhere and polymerize. As the HS can reduce the curing time, the polymerization process is controlled by the mass ratio between the amount of emulsifier, initiator dosage, HS oil, and the catalyst [32]. HS can form the PDMS to become gooey in texture with a soft structure. As the water and HS increase, the sample becomes more rigid and cloudy in appearance [31]. The addition of water induces moisture content into the phantom material. The moisture in the composites may interfere with the absorption effects by decreasing the effects of physical bonding and potentially acting as a lubricant between the polymer phases. A study by Sombatsompop and Sims (2004) suggested that to optimize the mechanical properties of polymers, the moisture content in the compound should be less than $1 \%$ [33].

$\mathrm{X}$-rays and gamma rays are penetrating forms of high-energy electromagnetic radiation. The photon mass attenuation coefficient, effective atomic number, and half value layer are the basic quantities required for determining the penetration of $\mathrm{X}$-rays and gamma rays in the matter [34]. The attenuation properties of this sample were studied to ensure that it could mimic the human tissue. Therefore, Phy-X/PSD software was utilized to calculate the $\mathrm{Z}_{\text {eff }}$ [35]. The effective atomic number was constant in the intermediateenergy region, whereas noticeable variation was observed for low $(<20 \mathrm{keV})$, as well as high-energy regions. Overall, the PDMS $Z_{\text {eff }}$ ranged around 4.00 to 5.00 in a higher energy range $\geq 1.00 \times 10^{-1} \mathrm{MeV}$ and was comparable with the previous work [19]. This $\mathrm{Z}_{\text {eff }}$ was lower at the intermediate energy range due to the dominance pair production and scattering effects. This sample showed a value of $Z_{\text {eff }}$ close to the normal kidney 
value with a deviation of seven to fifteen percent, as compared to the pure PDMS from our previous study [11]. The interaction of X-/gamma rays with different materials can be measured by using HVL. HVL provides a clear indication of the thickness needed to attenuate the half strength of the gamma-ray incident, and reveal the $\mathrm{X}$-ray penetration power. The HVL values increased with an increase in photon energy. Furthermore, it was also necessary to calculate the $Z_{\mathrm{eq}}$ factor for all materials to obtain the exposure buildup factor (EBF) and absorption process (EABF) [28]. It is vital to investigate the EBF and EABF as these characteristics will validate the material for medical application. The $Z_{\mathrm{eq}}$ values rose marginally at low energy levels and then increased significantly. The $Z_{\text {eq }}$ value for this study was higher than the lung, adipose tissues, and muscle, yet lower than the bone as its $Z_{\mathrm{eq}}$ at $0.015 \mathrm{MeV}$ measured 12.99 and rose till 14.12 at $1 \mathrm{MeV}$ [36,37]. The chemical composition, $Z_{\mathrm{eq}}$, plays a crucial role in the buildup of gamma photons within the selected human organs/tissues.

$\mathrm{CT}$ was used to determine the X-ray attenuation coefficient, and the CT number of water was set at $0 \mathrm{HU}$ [38]. For materials other than water and air, some dependence of the $\mathrm{CT}$ number on $\mathrm{kVp}$ was expected, primarily because of the photoelectric interaction's strong dependence on both photon energy and atomic number. Consequently, the mass attenuation coefficient of each material is highly dependent on energy; as a result, the CT number depends on $\mathrm{kVp}$ as well. For lower energy scans, such as 80 or $90 \mathrm{kVp}$, photoelectric interactions would be expected to increase, particularly in high- $Z$ material such as bone. Increased photoelectric interactions result in an increased measured CT number for high- $Z$ tissues at low $\mathrm{kVp}$, compared with the same tissues at higher energies. This supported the results for the sample containing HS and PDMS at the estimated ratio. Additionally, this aligned with Mustafa and Jackson, who showed that the CT number was dependent on the scan $\mathrm{kVp}$, particularly for high-Z/high-density materials [39,40]. Furthermore, it was reported that bone $\mathrm{CT}$ number decreases with an increase in $\mathrm{kVp}$.

As this CT number value fluctuates and is not constant, the image quality of the sample was evaluated. Based on Table 5, greater attenuation occurred at $120 \mathrm{kVp}$, reducing the signal received by the detector, which explained the lower SNR values. In a noisy image, the image contrast is low; this is caused by a large amount of background signal due to the Compton scattering effect, consequently reducing the CNR of the image [21]. This explains why the $140 \mathrm{kVp}$ scan reduced the CNR by $90 \%$, compared with the $120 \mathrm{kVp}$ value. Therefore, any factor that affected the SNR affected the CNR as well.

As a result, the attenuation coefficient was highly dependent on the energy, and the photoelectric interaction was dominant at the lower energy range. In diagnostic imaging, the two predominant interactions between $\mathrm{X}$-ray photons and matter were the photoelectric effect (complete X-ray absorption) and the Compton interactions (X-ray scatter with fractional loss of $X$-ray energy). There was a shift from a predominance of the photoelectric effect to the Compton interactions from the lower energy range of medical imaging (20-50 keV) to the higher energy range (50-150 keV), in which X-ray attenuation was strongly related to the electron density or mass of the image material, as used by the method proposed by Phy-X/PSD and verified by the CT material.

\section{Conclusions}

Based on the stability validation from our initial works, it was found that there was an urgency to fabricate a solid phantom that was not made of a water-based material. The effect of water and HS on the chemical properties of PDMS was not significant. In contrast to the radiation properties, the HS reduced the mass attenuation coefficient and X-ray attenuation coefficient of the pure PDMS, thus mimicking the CT number and effective atomic number of the human kidney. In this study, it is promising to suggest PDMS as the material of choice to be used as a stable kidney phantom in terms of good agreement with compressive strength and radiation attenuation. Furthermore, the blended PDMS imitates human tissue more precisely, and permits a wide range of possibilities for testing and phantom designs. Hence, it promises to be of value for use in both research and clinical 
settings, as a reliable and accurate tool for the development of phantoms, especially for in-vitro phantoms.

Author Contributions: Data curation, I.K.; formal analysis, M.K.A.K., S.M. and Y.J.L.; investigation, I.K. and N.A.Z.; methodology, N.A.S.M.R.; project administration, H.R.A.R.; resources, M.K.A.K. and J.Y.C.L.; supervision, H.R.A.R.; validation, M.N.; visualization, Y.J.L.; writing—original draft, I.K.; writing-review and editing, M.K.A.K. All authors have read and agreed to the published version of the manuscript.

Funding: This work was supported by Universiti Putra Malaysia under Geran Inisiatif Pelajar Siswazah with the project number GP/IPS/UPM/9683700.

Institutional Review Board Statement: Not applicable.

Informed Consent Statement: Not applicable.

Data Availability Statement: Not applicable.

Acknowledgments: The authors would like to acknowledge KPJ Healthcare University College for the support of this research.

Conflicts of Interest: The authors declare no conflict of interest.

\section{References}

1. Mat Radzi, S.F.; Abdul Karim, M.K.; Saripan, M.I.; Abd Rahman, M.A.; Osman, N.H.; Dalah, E.Z.; Mohd Noor, N. Impact of Image Contrast Enhancement on Stability of Radiomics Feature Quantification on a 2D Mammogram Radiograph. IEEE Access 2020, 8, 127720-127731. [CrossRef]

2. Mut, N.A.I.C.; Bakar, N.H.A.; Kamal, I.; Suhaimi, S.A.A.; Mohammad, N.M.; Ahmad, R.; Zain, N.M. Knowledge and Awareness of Breast Self-Examination among Secondary School Girls in Seremban, Negeri Sembilan. Asian Pac. J. Cancer Care 2019, 4, 39-43. [CrossRef]

3. Zhang, F.; Zhang, H.; Zhao, H.; He, Z.; Shi, L.; He, Y.; Ju, N.; Rong, Y.; Qiu, J. Design and fabrication of a personalized anthropomorphic phantom using 3D printing and tissue equivalent materials. Quant. Imaging Med. Surg. 2019, 9, 94-100. [CrossRef] [PubMed]

4. Li, W.; Belmont, B.; Greve, J.M.; Manders, A.B.; Downey, B.C.; Zhang, X.; Xu, Z.; Guo, D.; Shih, A. Polyvinyl chloride as a multimodal tissue-mimicking material with tuned mechanical and medical imaging properties. Med. Phys. 2016, 43, 5577-5592. [CrossRef]

5. Adams, F.; Qiu, T.; Mark, A.; Fritz, B.; Kramer, L.; Schlager, D.; Wetterauer, U.; Miernik, A.; Fischer, P. Soft 3D-Printed Phantom of the Human Kidney with Collecting System. Ann. Biomed. Eng. 2017, 45, 963-972. [CrossRef] [PubMed]

6. Cropp, R.J.; Seslija, P.; Tso, D.; Thakur, Y. Scanner and kVp dependence of measured CT numbers in the ACR CT phantom. J. Appl. Clin. Med. Phys. 2013, 14, 338-349. [CrossRef]

7. Mull, R.T. Mass estimates by computed tomography: Physical density from CT numbers. Am. J. Roentgenol. 1984, 143, 1101-1104. [CrossRef]

8. Umale, S.; Deck, C.; Bourdet, N.; Dhumane, P.; Soler, L.; Marescaux, J.; Willinger, R. Experimental mechanical characterization of abdominal organs: Liver, kidney \& spleen. J. Mech. Behav. Biomed. Mater. 2013, 17, 22-33. [CrossRef] [PubMed]

9. Filippou, V.; Tsoumpas, C. Recent advances on the development of phantoms using 3D printing for imaging with CT, MRI, PET, SPECT, and ultrasound. Med. Phys. 2018, 45, e740-e760. [CrossRef]

10. Brisbane, W.; Bailey, M.R.; Sorensen, M.D. An overview of kidney stone imaging techniques. Nat. Rev. Urol. 2016, 13, 654-662. [CrossRef]

11. Izdihar, K.; Rashmizal, H.; Razak, A.; Supion, N.; Khalis, M.; Karim, A.; Osman, N.H.; Norkhairunnisa, M. Structural, Mechanical, and Dielectric Properties of Polydimethylsiloxane and Silicone Elastomer for the Fabrication of Clinical-Grade Kidney Phantom. Appl. Sci. 2021, 11, 1172. [CrossRef]

12. Klaus, R.; Niyazi, M.; Lange-Sperandio, B. Radiation-induced kidney toxicity: Molecular and cellular pathogenesis. Radiat. Oncol. 2021, 16, 43. [CrossRef] [PubMed]

13. Kamal, I.; Chelliah, K.K.; Mustafa, N. Estimates of average glandular dose with auto-modes of X-ray exposures in digital breast tomosynthesis. Sultan Qaboos Univ. Med. J. 2015, 15, e292-e296. [PubMed]

14. Karimi, A.; Shojaei, A. Measurement of the Mechanical Properties of the Human Kidney. IRBM 2017, 38, 292-297. [CrossRef]

15. Hill, D.J.T.; Preston, C.M.L.; Salisbury, D.J.; Whittaker, A.K. Molecular weight changes and scission and crosslinking in poly(dimethyl siloxane) on gamma radiolysis. Radiat. Phys. Chem. 2001, 62, 11-17. [CrossRef]

16. Sankır, M.; Küçükyavuz, Z.; Küçükyavuz, S. Synthesis and Characterization of Poly (dimethylsiloxane)-Polythiophene Composites. J. Appl. Polym. Sci. 2003, 87, 2113-2119. [CrossRef] 
17. Dalod, A.R.M.; Grendal, O.G.; Blichfeld, A.B.; Furtula, V.; Pérez, J.; Henriksen, L.; Grande, T.; Einarsrud, M.A. Structure and

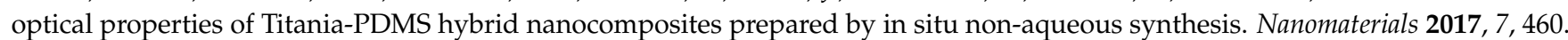
[CrossRef]

18. Şakar, E.; Özpolat, Ö.F.; Alım, B.; Sayyed, M.I.; Kurudirek, M. Phy-X / PSD: Development of a user friendly online software for calculation of parameters relevant to radiation shielding and dosimetry. Radiat. Phys. Chem. 2020, 166, 108496. [CrossRef]

19. Kamal, I.; Karim, M.K.A.; Harun, H.H.; Abdul Razak, H.R.; Jian, L.Y.; Chyi, J.L.Y.; Kechik, M.M.A. Evaluation of radiation attenuation properties on a various composition of polydimethylsiloxane (PDMS) for fabrication of kidney phantom. Radiat. Phys. Chem. 2021, 189, 109661. [CrossRef]

20. Harun, H.H.; Abdul Karim, M.K.; Muhammad, N.A.; Awang Kechik, M.M.; Chew, M.T.; Talib, Z.A. Task-based assessment on various optimization protocols of computed tomography Pulmonary Angiography examination. Radiat. Phys. Chem. 2021, 188, 109692. [CrossRef]

21. Muhammad, N.A.; Kayun, Z.; Abu Hassan, H.; Wong, J.H.D.; Ng, K.H.; Karim, M.K.A. Evaluation of Organ Dose and Image Quality Metrics of Pediatric CT Chest-Abdomen-Pelvis (CAP) Examination: An Anthropomorphic Phantom Study. Appl. Sci. 2021, 11, 2047. [CrossRef]

22. Harun, H.H.; Abdul Karim, M.K.; Abd Rahman, M.A.; Abdul Razak, H.R.; Che Isa, I.N.; Harun, F. Establishment of CTPA Local Diagnostic Reference Levels with Noise Magnitude as a Quality Indicator in a Tertiary Care Hospital. Diagnostics 2020, 10, 680. [CrossRef]

23. Li, Z.; Zhou, Z.; Li, Y.; Tang, S. Effect of Cyclic Loading on Surface Instability of Silicone Rubber under Compression. Polymers 2017, 9, 148. [CrossRef]

24. Wang, Z.; Volinsky, A.A.; Gallant, N.D. Crosslinking effect on polydimethylsiloxane elastic modulus measured by custom-built compression instrument. J. Appl. Polym. Sci. 2014, 131, 41050. [CrossRef]

25. Johnston, I.D.; McCluskey, D.K.; Tan, C.K.L.; Tracey, M.C. Mechanical characterization of bulk Sylgard 184 for microfluidics and microengineering. J. Micromech. Microeng. 2014, 24, 035017. [CrossRef]

26. Pan, Y.; Zhu, F.; Fan, J.; Tao, J.; Lin, X.; Wang, F.; Shi, L. Investigation of mechanical properties of silicone/phosphor composite used in light emitting diodes package. Polymers 2018, 10, 195. [CrossRef]

27. King, B.W.; Landheer, K.A.; Johns, P.C. X-ray coherent scattering form factors of tissues, water and plastics using energy dispersion. Phys. Med. Biol. 2011, 56, 4377-4397. [CrossRef] [PubMed]

28. Böke, A. Linear attenuation coefficients of tissues from $1 \mathrm{keV}$ to $150 \mathrm{keV}$. Radiat. Phys. Chem. 2014, 102, 49-59. [CrossRef]

29. Manjunatha, H. Comparison of effective atomic numbers of the cancerous and normal kidney tissue. Radiat. Prot. Environ. 2015, 38, 83. [CrossRef]

30. Grantham, K.; Li, H.; Zhao, T.; Klein, E. SU-E-CAMPUS-J-06: The Impact of CT-Scan Energy On Range Uncertainty in Proton Therapy Planning. Med. Phys. 2014, 41, 387. [CrossRef]

31. In, E. Development of Polymer-Based Gels for Multimodal Medical Imaging Phantoms; ProQuest LLC: Toronto, ON, Canada, 2016; p. 122.

32. Artikboeva, R.; Yang, M.; Wu, Y.; Jie, C.; Heng, Q. Preparation and Application of the Hydrophilic Amino-Silicone Softener by Emulsion Polymerization. Adv. Chem. Eng. Sci. 2020, 10, 1-23. [CrossRef]

33. Sombatsompop, N.; Chaochanchaikul, K. Effect of moisture content on mechanical properties, thermal and structural stability and extrudate texture of poly(vinyl chloride)/wood sawdust composites. Polym. Int. 2004, 53, 1210-1218. [CrossRef]

34. Akça, B.; Erzeneoğlu, S.Z. The mass attenuation coefficients, electronic, atomic, and molecular cross sections, effective atomic numbers, and electron densities for compounds of some biomedically important elements at $59.5 \mathrm{kev}$. Sci. Technol. Nucl. Install. 2014, 2014, 901465. [CrossRef]

35. Rashad, M.; Tekin, H.O.; Zakaly, H.M.; Pyshkina, M.; Issa, S.A.M.; Susoy, G. Physical and nuclear shielding properties of newly synthesized magnesium oxide and zinc oxide nanoparticles. Nucl. Eng. Technol. 2020, 52, 2078-2084. [CrossRef]

36. Kadri, O.; Alfuraih, A. Photon energy absorption and exposure buildup factors for deep penetration in human tissues Photon energy absorption and exposure buildup factors for deep penetration in human tissues. Nucl. Sci. Tech. 2019, 30, 176. [CrossRef]

37. Manohara, S.R.; Hanagodimath, S.M.; Gerward, L. Energy absorption buildup factors of human organs and tissues at energies and penetration depths relevant for radiotherapy and diagnostics. J. Appl. Clin. Med. Phys. 2011, 12, 296-312. [CrossRef] [PubMed]

38. He, T.; Qian, X.; Zhai, R.; Yang, Z. Computed tomography number measurement consistency under different beam hardening conditions: Comparison between dual-energy spectral computed tomography and conventional computed tomography imaging in phantom experiment. J. Comput. Assist. Tomogr. 2015, 39, 981-985. [CrossRef]

39. Abbasova, N.; Yüksel, Z.; Abbasov, E.; Gülbiçim, H.; Ça, M. Investigation of gamma-ray attenuation parameters of some materials used in dental applications. Results Phys. 2019, 12, 2202-2205. [CrossRef]

40. Kirby, B.J.; Davis, J.R.; Grand, J.A.; Morgan, M.J. Extracting material parameters from x-ray attenuation: A CT feasibility study using kilovoltage synchrotron x-rays incident upon low atomic number absorbers. Phys. Med. Biol. 2003, 48, 3389. [CrossRef] 